\title{
Abundance of questing ticks and molecular evidence for pathogens in ticks in three parks of Emilia-Romagna region of Northern Italy
}

\author{
Sara Aureli ${ }^{1}$, Roberta Galuppi ${ }^{2}$, Fabio Ostanello' ${ }^{2}$, Janet E Foley ${ }^{3}$, Cristina Bonoli ${ }^{4}$, \\ Daniel Rejmanek ${ }^{3}$, Giorgia Rocchi', Elisa Orlandi', Maria Paola Tampieri ${ }^{2}$ \\ ${ }^{1}$ Veterinary practitioner, Modena, Italy \\ 2 Department of Veterinary Medical Sciences, Alma mater Studiorum - University of Bologna, Italy \\ ${ }^{3}$ University of California Davis, School of Veterinary Medicine, Dept. of Medicine and Epidemiology \\ ${ }^{4}$ Veterinary Practitioner, Forli- Cesena, Italy
}

Aureli S, Galuppi R, Ostanello F, Foley JE, Bonoli C, Rejmanek D, Rocchi G, Orlandi E, Tampieri MP. Abundance of questing ticks and molecular evidence for pathogens in ticks in three parks of Emilia-Romagna region of Northern Italy. Ann Agric Environ Med. $2015 ; 22(3)$ : $459-466$. doi: $10.5604 / 12321966.1167714$

\section{Abstract}

Introduction and objective. Infectious and parasitic diseases transmitted by ticks, such as Lyme diseases, granulocytic anaplasmosis and piroplasmosis, have been frequently reported in Europe, with increasing attention to them as an emerging zoonotic problem. The presented study was performed to assess the distribution and the density of questing ticks in three regional parks of Emilia-Romagna region of Northern Italy, and to seek molecular evidence of potential human pathogens in tick populations.

Materials and Methods. In the period April-October 2010, 8,139 questing ticks were collected: 6,734 larvae, 1,344 nymphs and only a few adults - 28 females and 33 males. The abundance of Ixodes ricinus questing ticks was compared among different sampling sites and related to microclimate parameters. 1,544 out of 8,139 ticks were examined for the presence of pathogens: PCR was used to detect piroplasms DNA and Real time Taqman PCR for Anaplasma phagocytophilum and Borrelia burgdorferi s.I.

Results. The predominant species was I. ricinus (overall abundance 1,075.9/100 $\mathrm{m}^{2}$ ); more rarely, Dermacentor marginatus $(n=37-0.45 \%)$, Scaphixodes frontalis $(n=13-0.16 \%)$, Hyalomma spp. $(n=6-0.07 \%)$ and Ixodes acuminatus $(n=3-0.04 \%)$ were also found. 28 out of 324 (8.6\%) samples of ticks were PCR-positive for piroplasm DNA. 11 amplicons of 18S rRNA gene were identical to each other and had $100 \%$ identity with Babesia EU1 (Babesia venatorum) using BLAST analysis. Real time Taqman PCR gave positive results for A. phagocytophilum in 23 out of 292 samples (7.9\%), and for B. burgdorferi s.l. in 78 out of 292 samples (26.7\%). I. ricinus was the only species found positive for pathogens by molecular analysis; 16 tick samples were co-infected with at least 2 pathogens.

Discussion. The peak of nymph presence was in May, and the higher prevalence of pathogens occurred in April-June, most often in nymphs; therefore, spring season could represent the higher risk period for the transmission of pathogens. These data could provide guidelines for the preventions of tick-trasmitted diseases in this region.

\section{Key words}

questing ticks, Ixodes ricinus, Babesia EU1, Anaplasma phagocytophilum, Borrelia burgdorferi s.l.; Emilia Romagna region (Italy)

\section{INTRODUCTION}

Ixodid ticks (hard ticks) are parasites of great importance for both animal and human health. They are able to harm the host, directly as bloodsucking parasites causing anaemia, toxicosis, paralysis and allergies, but they can also transmit pathogens. Infectious and parasitic diseases transmitted by ticks, such as Lyme diseases, granulocytic anaplasmosis and piroplasmosis, have been frequently reported in Europe, with increasing attention on them as an emerging zoonotic problem. In recent decades, in addition to climate change [1], the increase of wild animals in rural and peri-urban areas and the increased interest of people in outside activities, have led to closer contacts between people and the natural cycles in which ticks occur [2]. Monitoring of ticks, and in particular Ixodes ricinus, in areas used by people for

Address for correspondence: Roberta Galuppi, Department of Veterinary Medical Sciences, Alma mater Studiorum - University of Bologna, Via Tolara di Sopra, 50 40064, Ozzano Emilia Bologna, Italy

E-mail: roberta.galuppi@unibo.it

Received: 23 July 2014; accepted: 07 January 2015 recreational activities makes it possible to assess the risk of tick infestation and infection related to pathogens transmitted by these arthropods [3].

The distribution of ixodid ticks in Italy is influenced greatly by the different habitats present on the peninsula, from the Alps region to the far south of Sicily. The presented study was performed to assess the distribution and the density of ticks in 3 regional parks of the Emilia-Romagna Region of Northern Italy, in which no studies have been performed previously, and to seek molecular evidence in these tick populations of potential human pathogens, such as piroplasms, Anaplasma phagocytophilum and Borrelia burgdorferi s.l.

\section{MATERIALS AND METHOD}

Sampling. 4 sampling sites in 3 parks of the EmiliaRomagna Region of Northern Italy were selected for the study: the Regional park of 'Gessi Bolognesi and Calanchi dell'Abbadessa', the regional park of 'Monteveglio Abbey', both in Bologna Province, and 'Carnè' Park, within the 'Vena 


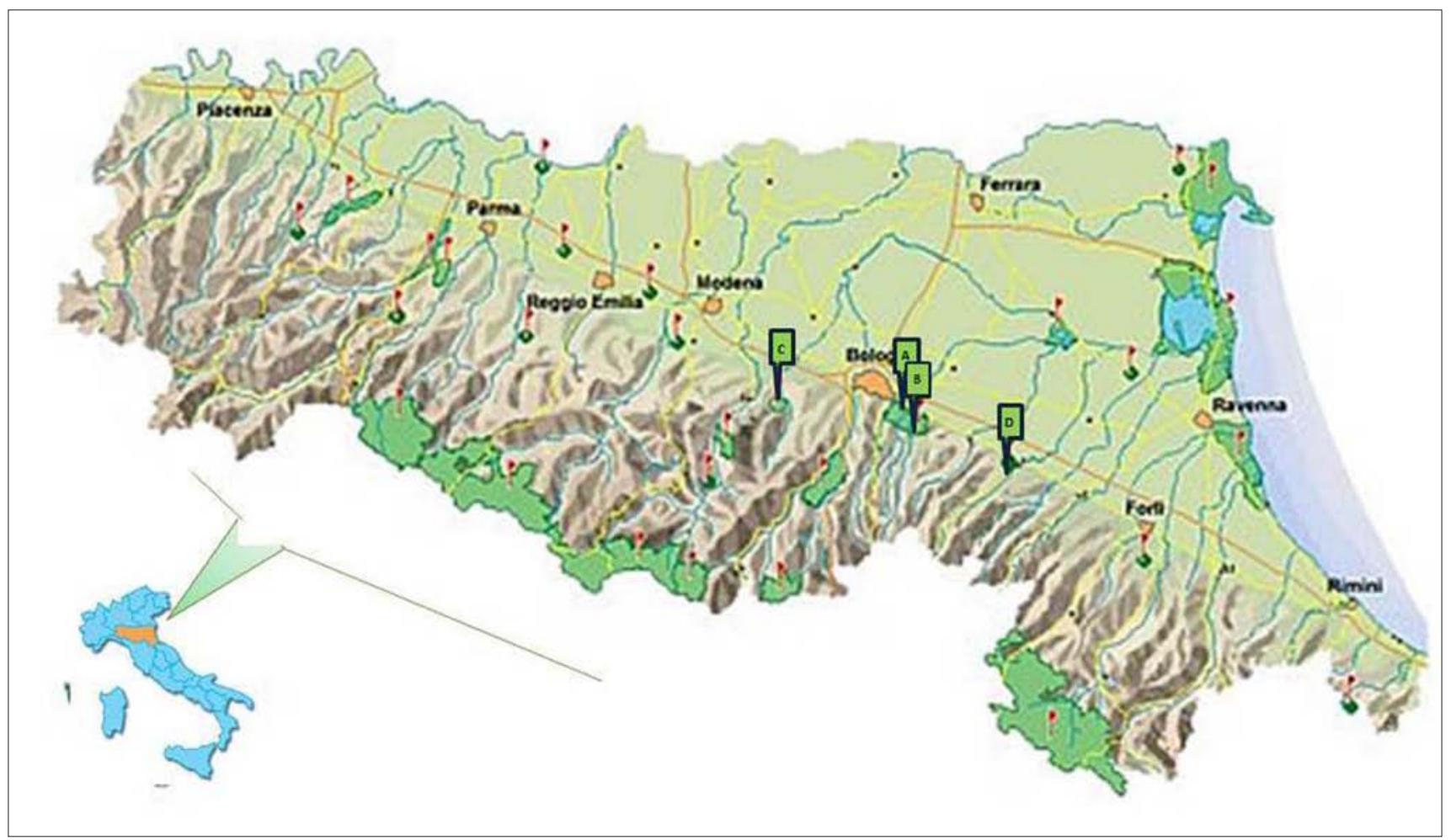

Figure 1. Sampling sites: A (locality "Ca' de Mandorli") and B (locality “Ciagnano") in the "Gessi Bolognesi and Calanchi dell'Abbadessa Park"; C - "Monteveglio Abbey park", D - "Carnè Park". Emilia Romagna Region, Italy

del Gesso Romagnola' regional park in Ravenna Province (Fig. 1). These parks are distributed along the hilly part of the Apennines, in a complex territory characterized by a series of gypsum outcrops, karst system with sinkholes, closed valleys, cliffs, wooded mountains, and grey calanques, alternated with agricultural areas, with the traditional hilltype configuration. At these sites there are natural pathways and picnic areas, interspersed with woods and meadows. The sampling was carried out in picnic areas and along footpaths that are usually frequented by people.

In the 'Gessi Bolognesi and Calanchi dell'Abbadessa' park, 2 sampling sites were selected: the first was situated in the

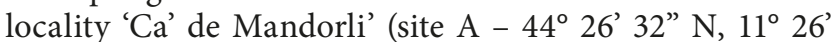
30 " E, $66 \mathrm{~m}$ asl). At this site, a wooded area of $35 \mathrm{~m}^{2}$ and 3 transects of $20 \mathrm{~m}$ at the border of a wood with grass mantle were selected. The second was located in locality 'Ciagnano' (site B $-44^{\circ} 24^{\prime} 57^{\prime \prime} \mathrm{N}, 11^{\circ} 27^{\prime} 16^{\prime \prime} \mathrm{E}, 240 \mathrm{~m}$ asl); at this site, 6 transects along a path, each of $20 \mathrm{~m}$, were sampled. At site C ( $44^{\circ} 28^{\prime} 01^{\prime \prime} \mathrm{N}, 11^{\circ} 5^{\prime} 14^{\prime \prime} \mathrm{E} 252 \mathrm{~m}$ asl), located in the 'Monteveglio Abbey' park, 6 transects - each of $20 \mathrm{~m}$, along the pathway, and 2 transects - each of $30 \mathrm{~m}$, at a border of

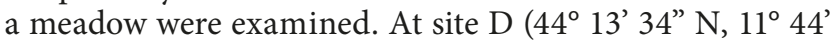
22” E $387 \mathrm{~m}$ asl), 'Carnè', an area of $236 \mathrm{~m}^{2}$, including a playground and a picnic zone, and 6 transects - each of $20 \mathrm{~m}$ along a path, were choosen.

The areas selected were indicated by barrier tape and sampled every 15 days for questing ticks, from April October 2010 (from May - October at site D, because the park was closed in April). Ticks were collected by continuously flagging with a $1 \mathrm{~m} \times 1 \mathrm{~m}$ white cotton cloth, from transects of $20 \mathrm{~m}$ along the uphill side of the paths, which typically has higher tick densities than the downhill side [4], while the areas were flagged completely. The total surface flagged was $95 \mathrm{~m}^{2}$ at site A, $120 \mathrm{~m}^{2}$ at site B, $180 \mathrm{~m}^{2}$ at site C and $356 \mathrm{~m}^{2}$ at site $\mathrm{D}$. The ticks were removed every $2 \mathrm{~m}$ to reduce the effect of tick drop-off [5].

Collected ticks were immediately put into $70 \%$ ethanol and stored at room temperature until morphological identification, made by using identification keys $[6,7]$, and subsequent DNA extraction. The number of ticks, species and stage of development were recorded for each transect or area. During each sampling day and in each transect or area examined, environmental factors were recorded, such as the dominant vegetation (presence of grass or dry leaf litter) and the microclimate, assessed by measuring air temperature and percentage of humidity at $5 \mathrm{~cm}$ above the soil [8] using a thermometer with hygrometer (Oregon Scientific, USA).

DNA analyses. Ticks were processed individually when adults, or in pools of 5 nymphs or 10 larvae [9]. Each pool consisted of ticks from the same site and time of sampling. Overall, 1,544 ticks (324 samples) were examined as follows: 320 larvae of $I$. ricinus (32 samples) 1,165 nymphs (232 samples of $I$. ricinus and 1 Scaphixodes frontalis) and 59 adults (52 I. ricinus, 3 Ixodes acuminatus, 1 Dermacentor marginatus 3 Hyalomma m. marginatum). Ticks were washed twice with PBS and centrifuged at 10,000 $\mathrm{x}$ g for one minute to remove the alcohol, then cut with a steril scalpel. DNA was extracted with Nucleo Spin Extract II (Macherey Nagel), according to manufacturer's instructions, except for an increased period of lysis of ticks from $10 \mathrm{~min}$ to $30 \mathrm{~min}$.

All the tick samples $(n=324)$ were examined for piroplasms DNA. PCR assays were performed amplifying $400 \mathrm{bp}$ of $18 \mathrm{~S}$ rRNA gene of piroplasms [10]. All the PCR products were purified using NucleoSpin Extract II (Macherey Nagel $\mathrm{GmbH}$, Düren, Germany), and both strands were sequenced by BMR genomics (Padua, Italy) in an ABI-3730XL analyzer. 
The sequences were corrected by visual analysis in BioEdit 7.0.9 and subjected to database search by BLAST.

292 samples (nymphs and adults; no larvae were examined) were tested for the presence of A. phagocytophilum DNA with highly sensitive real-time Taqman PCR (StepOnePlus, Applied Biosystem, Life Technologies Corporation, Carlsbad, California, USA) assay targeting the multiple-copy msp2/p44 gene [11]. Samples with a cycle threshold (Ct) value of $<40$ and a characteristic amplification curve were considered positive.

The same 292 samples were also screened for the presence of B. burgdorferi s.l. DNA with highly-sensitive real-time Taqman PCR (StepOnePlus, Applied Biosystem, Life Technologies Corporation, Carlsbad, California, USA) assay targeting 16S rDNA region, according to Barbour et al. [12], modified by increasing the number of cycles to 50 , rather than 45 , and decreasing the extention temperature to $60^{\circ} \mathrm{C}$ instead of $63^{\circ} \mathrm{C}$. Samples with a cycle threshold (Ct) value of $<40$ and a characteristic amplification curve were considered positive.

Statistical analysis. To compare between sampling sites, data on I. ricinus - the species mainly represented - were converted to abundance indices (AI), which express the number of ticks collected in $100 \mathrm{~m}^{2}$. This parameter was calculated for the total of ticks (AI), and larvae (AIL), nymphs (AIN) and adults (AIA), according to the formula AI=TR x 100/a, where 'TR' is the number of I. ricinus ticks recorded and 'a' is the sampled area in square meters [13]. The non-parametric KruskallWallis test was used to compare tick abundance among the different sampling sites. Non-parametric correlation (Spearman Rho) was used to assess the relationship between microclimate parameters (temperature, humidity) and ticks abundance. An $\chi^{2}$ test was performed to evaluate different positive rates of pathogens in ticks among sampling sites, month of sampling, temperature $\left(\mathrm{T}^{\circ}\right)$ and humidity $(\mathrm{RH})$ at the time of sampling, and among nymphs and adults of I. ricinus. Values of $\mathrm{p}<0.05$ were considered statistically significant. Statistical analysis was performed by SPSS software (IBM SPSS Statistics ver. 21).

\section{RESULTS}

Tick abundance. During the period April-October 2010, 8,139 ticks were collected at the 3 sites. The highest number of ticks was found at site B $(4,187)$, followed by site A $(2,123)$, then site D (967), and finally site C (862). The majority were larvae $(6,734)$ and to a lesser extent nymphs $(1,344)$; only a few specimens collected were adults (28 females and 33 males). The predominant species was $I$. ricinus $(\mathrm{n}=8080-99.28 \%)$; rarely, Ixodes acuminatus ( $\mathrm{n}=3-0.04 \%)$, Dermacentor marginatus $(\mathrm{n}=37-0.45 \%)$, Scaphixodes frontalis $(\mathrm{n}=13$ $0.16 \%)$ and Hyalomma spp. $(\mathrm{n}=6-0.07 \%)$ were also found (Tab. 1).

The greatest richness of tick species were detected at site B. Since species other than $I$. ricinus were found in smaller numbers and only occasionally, only this latter species was taken in account for the following considerations. The overall abundance of $I$. ricinus was $1,075.9 / 100 \mathrm{~m}^{2}$, with a greater abundance of larvae $\left(891.3 / 100 \mathrm{~m}^{2}\right)$ than nymphs $\left(150.9 / 100 \mathrm{~m}^{2}\right)$ and adults $\left(7.1 / 100 \mathrm{~m}^{2}\right)$. AI, AIL and AIN were significantly higher at site $B$ than the other sites $(\mathrm{p}<0.01$ for AI and AIL and $\mathrm{p}<0.05$ for AIN) (Tab. 2).
Table 1. Number of ticks collected from four sampling sites*, divided into stages of development and sampling site

\begin{tabular}{|c|c|c|c|c|c|c|}
\hline SPECIES & STAGES & SITE A & SITE B & SITE C & SITE D & TOTAL \\
\hline \multirow[t]{4}{*}{ I. ricinus } & Larvae & 1876 & 3614 & 520 & 684 & 6694 \\
\hline & Nymphs & 242 & 493 & 330 & 268 & 1333 \\
\hline & Females & 2 & 11 & 6 & 3 & 22 \\
\hline & Males & 2 & 16 & 6 & 7 & 31 \\
\hline \multirow[t]{2}{*}{ I. acuminatus } & Females & & 2 & & & 2 \\
\hline & Males & & & & 1 & 1 \\
\hline \multirow[t]{3}{*}{ S. frontalis } & Larvae & & & & 1 & 1 \\
\hline & Nymphs & & 9 & & 2 & 11 \\
\hline & Females & & & & 1 & 1 \\
\hline \multirow[t]{2}{*}{ D. marginatus } & Larvae & & 36 & & & 36 \\
\hline & Females & 1 & & & & 1 \\
\hline \multirow[t]{4}{*}{$\begin{array}{l}\text { H. marginatum } \\
\text { marginatum }\end{array}$} & $\begin{array}{l}\text { Larvae } \\
\text { (Hyalomma sp.) }\end{array}$ & & 3 & & & 3 \\
\hline & Females & & 2 & & & 2 \\
\hline & Males & & 1 & & & 1 \\
\hline & & 2123 & 4187 & 862 & 967 & 8139 \\
\hline
\end{tabular}

* Sampling sites: A - 'Ca' de Mandorli'; B - 'Ciagnano', both in the 'Gessi Bolognesi and Calanchi dell'Abbadessa Park'; C - 'Monteveglio Abbey Park'; D - 'Carnè Park'; Emilia Romagna Region, Italy.

Table 2. Mean abundance of larvae, nymphs and adult of $I$. ricinus per sampling site sa* $^{* *}$

\begin{tabular}{lcccc}
\hline \multirow{2}{*}{$\begin{array}{l}\text { Site of } \\
\text { sampling }\end{array}$} & \multicolumn{4}{c}{ Abundance: mean (standard deviation) } \\
\cline { 2 - 5 } & total ticks $/ 100 \mathrm{~m}^{2}$ & larvae $/ 100 \mathrm{~m}^{2}$ & nymphs $/ 100 \mathrm{~m}^{2}$ & adults $/ 100 \mathrm{~m}^{2}$ \\
\hline Site A & $147.23(271.48)$ & $124.12(27881)$ & $22.78(37.12)$ & $0.32(0.84)$ \\
\hline Site B & $246.07(333.88)^{*} \mathrm{a}$ & $215.11(345.43)^{*} \mathrm{a}$ & $29.34(38.35)^{*} \mathrm{~b}$ & $1.60(2.70)$ \\
\hline Site C & $34.21(35.91)$ & $20.63(28.84)$ & $13.09(21.09)$ & $0.48(0.92)$ \\
\hline Site D & $44.63(59.38)$ & $33.34(57.37)$ & $10.90(25.69)$ & $0.39(1.23)$ \\
\hline Total & $106.27(216.68)$ & $87.52(219.06)$ & $18.08(30.78)$ & $0.66(1.60)$
\end{tabular}

*significantly higher than other sites; $a=p<0.01 ; b=p<0.05$.

** Sampling sites: A - 'Ca' de Mandorli'; B - 'Ciagnano" both in the 'Gessi Bolognesi and Calanchi dell'Abbadessa Park'; C - 'Monteveglio Abbey park', D - 'Carnè Park'; Emilia Romagna Region, Italy

The peak of AIL was recorded in July at sites A, B and C, while at site D the peak occurred in August. At site C, where the AIL was lower, another peak was present in May. The peak of AIN (at a lower level than AIL) occurred in May at all the sites. The occurrence of adult ticks was rather sporadic and fairly distributed throughout the sampling, with a peak in April-May at site B (Fig. 2).

The temperature registered at $5 \mathrm{~cm}$ above the soil during the sampling period ranged from $10.7-37.9^{\circ} \mathrm{C}$. At all the sites, a higher AIL was observed at temperature $>30^{\circ} \mathrm{C}$, while the main AIN was observed at temperature less than $22^{\circ} \mathrm{C}$. No adults were found at temperature $>30^{\circ} \mathrm{C}$. Overall, in the range examined, there was a significant correlation between abundance of collected questing ticks and temperature: AIL tends to increase with the increase in temperature, versus the AIN and AIA which tended to decrease (Fig. 3). The RH ranged from $23 \%-81 \%$. No significant differences in IAL, IAN and IAA were found at the different $\mathrm{RH}$, although the AIL was higher at low RH (Fig. 3).

Finally, considering the dominant vegetation (presence of grass or dry leaf litter), it was observed that AIL and AIN were higher on dry leaf litter than on grass (Fig. 4). 


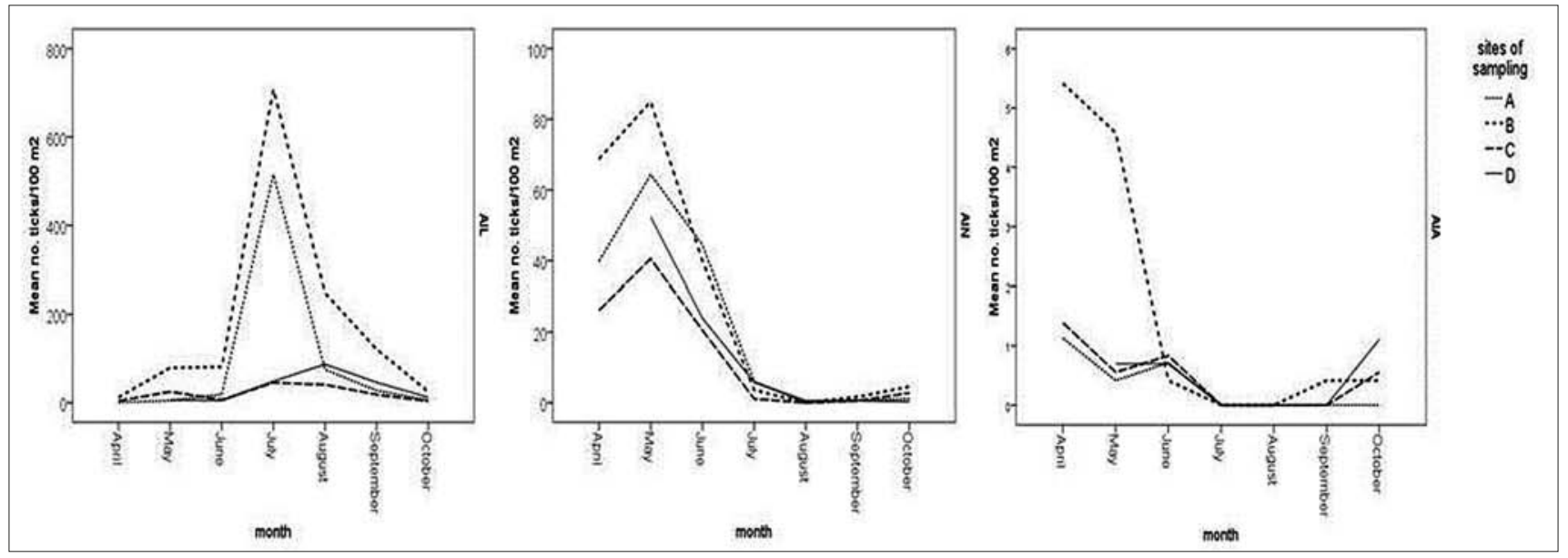

Figure 2. Tick abundance during the time in the different sampling sites.

A (locality "Ca' de Mandorli") and B (locality "Ciagnano") in the "Gessi Bolognesi and Calanchi dell'Abbadessa Park"; C - "Monteveglio Abbey park", D - "Carnè Park"; AlL larvae abundance, AIN nimph abundance, AIA adult abundance

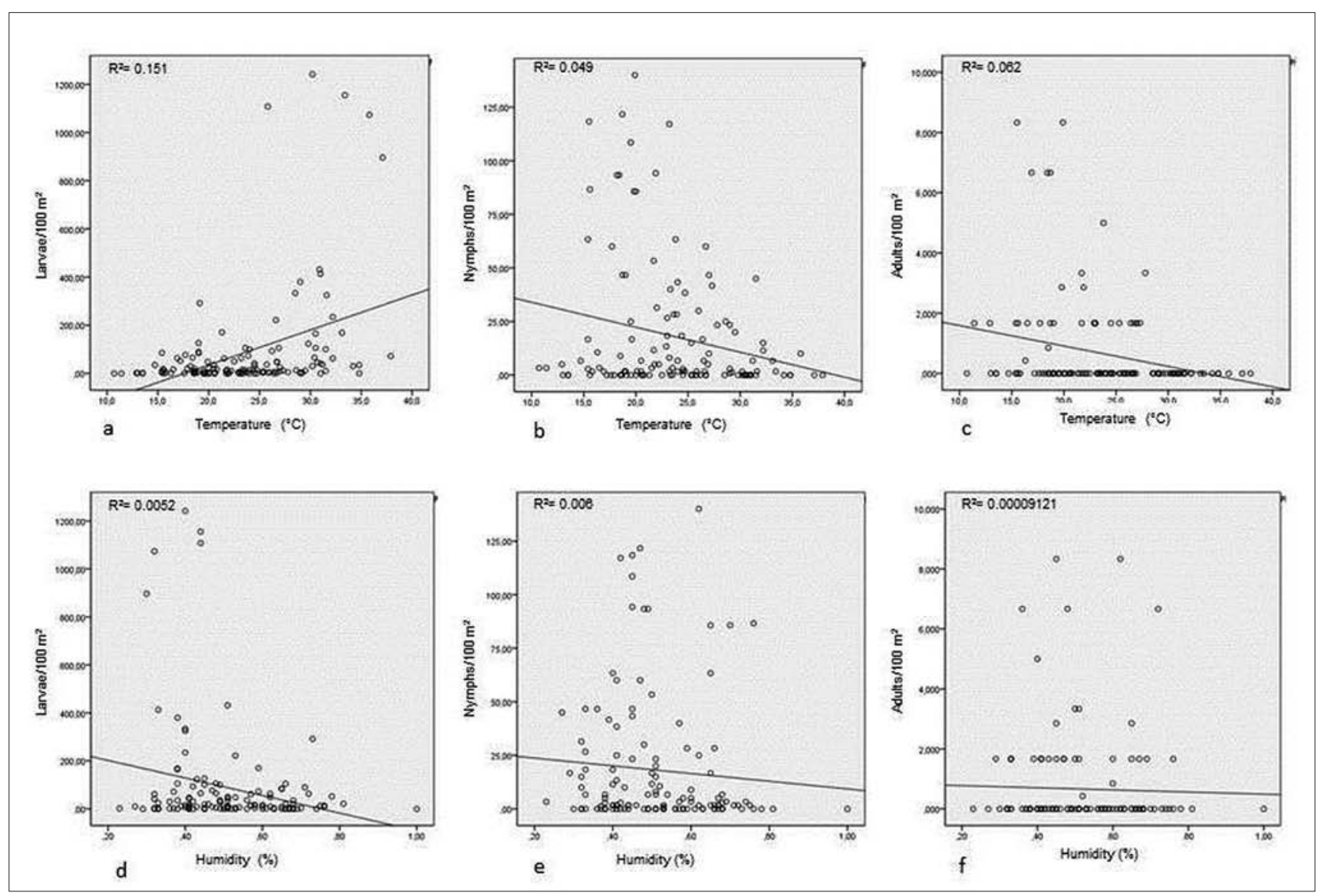

Figure 3. Abundance of larvae, nymphs and adults at different temperature $(a, b, c)$ and percentage of humidity $(d, e, f)$ registered at $5 \mathrm{~cm}$ above the soil

Piroplasms. Overall, 28 out of 324 (8.6\%) samples of ticks examined for piroplasms DNA were positive by PCR. From all sampling sites, only I. ricinus ticks were found positive: 2 male, one female and 25 pools of nymphs (Tab. 3); no larval samples were tested positive. Prevalence was significantly higher in site $\mathrm{C}(\mathrm{p}<0.05)$. Independently from the sampling site, PCR-positive ticks were collected only in April, May and June, with a higher prevalence in May (14.8\%). Prevalence was higher in specimens collected at temperature $>35^{\circ} \mathrm{C}$ (28.6\%), and/or at $\mathrm{HR}<30^{\circ} \mathrm{C}(18.2 \%)$; however these data were not statistically significant.
11 amplicons from 9 pools of nymph and 2 adults from all sites were identical to each other, and the sequences showed $100 \%$ identity with Babesia EU1 (B. venatorum) (AY046575 and other strains) by BLAST analysis.

The amplicons from 2 pools of nymphs collected at site D had 99\% identity with B. divergens (AY572456) and B. capreoli (FJ944828). 15 isolates from sites A, B and C, identity varyng from $85 \%$ - to $100 \%$ with different strains of Theileria buffeli, T. sergenti. and T. orientalis, and were therefore included in the T. buffeli/sergenti/orientalis complex. 


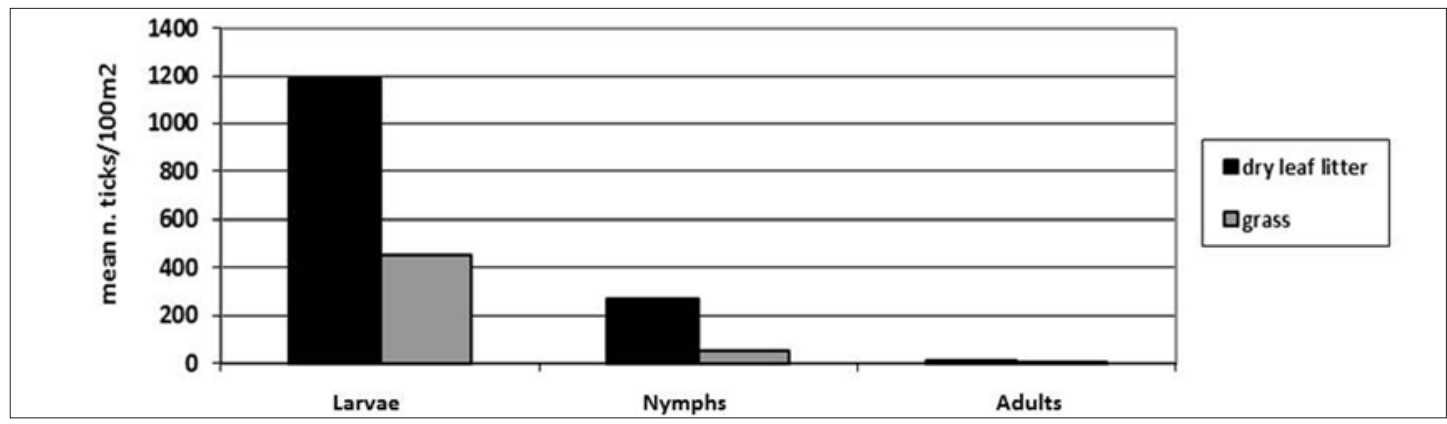

Figure 4. Mean abundance of larvae, nymphs and adult ticks collected in different dominant vegetation (presence of grass or dry leaf litter)

Table 3. I. ricinus samples positive for piroplasms, A. phagocytophylum and B. burgdorferi s.l. by PCR (none of the other tick species tested positive and are not included in the Table). Note: each samples consist of individual adults, or 5 nymphs or 10 larvae

\begin{tabular}{|c|c|c|c|c|c|}
\hline & \multicolumn{5}{|c|}{ n. positive to $P C R /$ n. examined (\%) } \\
\hline & Site A & Site B & Site C & Site D & Total \\
\hline \multicolumn{6}{|l|}{ Piroplasms } \\
\hline Adult male & $0 / 2$ & $\begin{array}{c}1 / 15(6.7) \\
1 \text { (EU1) }\end{array}$ & $\begin{array}{c}1 / 7(14.3) \\
1 \text { (th) }\end{array}$ & $0 / 7$ & $2 / 31(6.4)$ \\
\hline Adult female & $0 / 2$ & $\begin{array}{c}1 / 12(8.3) \\
1 \text { (EU1) }\end{array}$ & $0 / 4$ & $0 / 3$ & $1 / 21(4.8)$ \\
\hline Larvae & $0 / 11$ & $0 / 21$ & - & - & $0 / 32(0 \%)$ \\
\hline Total & $2 / 58(3.4)$ & $11 / 137(8.0)-$ & 12 /67 (17.9) & $3 / 54(5.6)$ & $28 / 316(8.9)$ \\
\hline \multicolumn{6}{|c|}{ Anaplasma phagocytophylum } \\
\hline Adult male & $0 / 2(0)$ & $2 / 15(13.3)$ & 2/7 (28.6) & $0 / 7(0)$ & $4 / 31(8.9)$ \\
\hline Adult female & $0 / 2(0)$ & $0 / 12(0)$ & $0 / 4(0)$ & $0 / 3(0)$ & $0 / 21(0)$ \\
\hline Total & $5 / 47(10.6)$ & $8 / 116(6.9 \%)$ & $10 / 67(14.9)$ & $0 / 54(0)$ & $23 / 284(8.1)$ \\
\hline \multicolumn{6}{|c|}{ Borrelia burgdorferi s.l. } \\
\hline Adult male & $0 / 2$ & $1 / 15(6.7)$ & 2/7 (28.6) & $1 / 7(14.3)$ & 4/31 (12.9) \\
\hline Adult female & $1 / 2(50)$ & $1 / 12(8.3)$ & $1 / 4(25)$ & $1 / 3(33.3)$ & 4/21 (19) \\
\hline Nymph & $17 / 43(39.5)$ & $25 / 89(28)$ & $14 / 56(25)$ & $14 / 44(31.8)$ & $70 / 232(30.2)$ \\
\hline Total & $18 / 47(38.3)$ & $27 / 116(23.3)$ & $17 / 67(25.4)$ & $16 / 44(36.4)$ & $78 / 284(27.5)$ \\
\hline
\end{tabular}

EU1 - isolates with $100 \%$ identity with Babesia EU1 AY046575; Bc/d - isolates with $99 \%$ identity with B. capreoli FJ944828 and B. divergens AY572456; Th - isolates with $85 \%$ - $100 \%$ identity with Theileria buffeli/sergenti/orientalis

Anaplasma phagocytophilum. A total of 23 samples out of 292 (7.9\%) tested positive for A. phagocytophilum infection by real-time PCR. I. ricinus was the only species found positive, including $8.9 \%$ of males and $8.2 \%$ of pools of nymphs. No female tick was found positive and no positive samples were found at site $\mathrm{D}$ (Tab. 3). The prevalence of A. phagocytophilum was significantly higher in April (15.8\%) than in May (5.7\%; $\mathrm{p}=0.03$ ) and June $(4.2 \% ; \mathrm{p}=0.037)$; no positive samples were found in ticks collected in the other months. Furthermore, the prevalence was significantly higher $(\mathrm{p}<0.05)$ in ticks collected at $20-26^{\circ} \mathrm{C}(18.8 \%)$, compared to ticks collected at higher or lower temperatures $(4.6 \%-4.9 \%$ or negative). There were not significant differences between ticks collected at different $\mathrm{RH}$.

Borrelia burgdorferi s.l. Real time taqman PCR for B. burgdorferi s.l. was positive in 78 out of 292 samples (26.7\%). Only I. ricinus was found to be positive (Tab. 3). No statistically significant differences were found in prevalence between different sites of sampling, while the prevalence was higher in nymphs than adults ( $30.2 \%$ vs. $12.9 \%$; $<<0.01)$. The prevalence of B. burgdorferi s.l. in ticks was higher in April, May and
June, but the difference compared to the other months was not statistically significant. No differences were found between ticks collected at different temperatures and $\mathrm{RH}$.

16 tick samples were co-infected with at least 2 of the pathogens mentioned above (Tab. 4). The association of

Table 4. Co-infections in I. ricinus ticks samples from the different sampling sites*

\begin{tabular}{lcccc}
\hline Concomitant infection & SITE A & SITE B & SITE C & SITE C \\
\hline $\begin{array}{l}\text { A. phagocytophilum/ } \\
\text { B. burgdorferi s.l. }\end{array}$ & 2 nymphs & 1 nymph & $\begin{array}{c}1 \text { nymph }+ \\
1 \text { male }\end{array}$ & 1 male \\
\hline $\begin{array}{l}\text { A. phagocytophilum/ } \\
\text { Babesia EU1 }\end{array}$ & 1 nymph & 1 male & - & - \\
\hline
\end{tabular}

\section{B. burgdorferi s.I.}

BabesiaEU1.

3 nymphs

B. burgdorferi s.I./

B. divergens-capreoli

B. burgdorferi s.l./

Theileria spp.

1 nymph

* A (locality 'Ca' de Mandorli'. B - 'Ciagnano', both in the 'Gessi Bolognesi and Calanchi dell'Abbadessa' Park; C - 'Monteveglio Abbey' Park; D - 'Carnè' Park; Emilia Romagna Region, Italy 
A. phagocytophilum/B. burgdorferi s.l. was more frequent (6 samples) and was found in ticks from all the sampling sites

\section{DISCUSSION}

The diversity of tick species found in this study was higher than in other studies conducted in other parks of the Emilia Romagna region [14], which found only I. ricinus by dragging; in contrast, a higher richness of species diversity was recently found in an oak forest of South Italy [15]. The recovery of S. frontalis (one larva, 11 nymphs and one female) at sites $A$ and $D$ is interesting. Males were not detected and are rarely described in the literature. This tick, parasitizing primarily avian species, especially Passeriformes, has been reported in most regions of Italy, but to-date, there have been no reports of its presence in the Emilia-Romagna Region [6,7], although it is not surprising that it should be in that region as it is easily transported by birds during migration.

Ixodes ricinus is by far the most common species in Europe and also in the current study, it appears to be the predominant species, with 8,080 specimens collected. This species was reported at all the sampling sites, although some differences in AI were found that related to the developmental stage, sampling site, collection period, microclimate (temperature and humidity) and vegetation at the site of sampling. AIL was higher than AIN and AIA according to Barandika et al. [13] in Northern Spain and by Dantas Torres and Otranto [15] in Southern Italy. A decreased presence of mature stages, with respect to juveniles, is not surprising, because only $0.1 \%$ of the eggs produced by the female can reach the adult stage [16]. In the presented study, the detection of adults was rather sporadic and distributed throughout the sampling period. The overall AIA $\left(7.1 / 100 \mathrm{~m}^{2}\right)$ was similar to the finding reported by Barandika et al. [13]. The highest AI of I. ricinus was observed at site $\mathrm{B}$, where the ixodid tick species richness was highest overall; this was probably related to the presence of a rich and varied local fauna, as the sampling was performed along a narrow path that winds through the hilly terrain in a forest at the edge of the calanques. Randolph et al. [17] in England showed that, despite annual differences, the larvae show a higher peak around the month of July, while the nymphs show a greater activity in May, which is in agreement with the presented results and counter to those of Barandika et al. [13] in Northern Spain.

During sampling, an increase of AIL with increasing temperature was observed, but the data obtained are not completely in accord with other authors [3] who reported reduced activities of ticks when the temperature is higher. The larval stages are usually considered more sensitive to high temperatures, and various authors indicate the temperatures of $32{ }^{\circ} \mathrm{C}$ as critical for the survival of I. ricinus, because they cause rapid dehydration [18]. Usually, it is presumed that moisture is a crucial factor for the survival of I. ricinus; larvae and nymphs choose micro-habitats in which the relative humidity is above $80 \%$ to avoid desiccation [19]. The active, seeking ticks, in order to avoid dehydration, tend to penetrate into the upper layers of soil, or beneath the foliage at the base of vegetation, where high humidity creates a microclimate that allows rehydration. Once rehydrated, the young and hungry ticks tend to climb on the top layers of turf or leaves on the forest floor where they have a high host-seeking activity [20]. In the presented work, it was observed that the abundance of larvae tends to decrease with increasing humidity, with the highest AIL when the humidity was less than $35 \%$; this can be explained by the fact that the ticks collected by flagging were those in active search of a host, and increased their activity precisely when the humidity was low [20]. There was a greater abundance of I. ricinus, especially larvae and nymphs, in woodland areas where grass was not present and there was a small shrub vegetation and ground covered with dry leaves. The data obtained can be explained by the fact that the areas presenting turf were also more exposed to the sun, which probably limited the active presence of ticks in the upper layers, reducing the attack of the flag.

The presented study also investigated molecular evidence of potential zoonotic agents. Out of 324 samples, $8.6 \%$ tested positive for piroplasms by PCR. Data in the literature from European countries show extremely variable prevalences ranging from $1 \%$ in Germany [21] up to $60 \%$ in Poland [22]. Also, in the presented study different infection rates of piroplasms in ticks were detected depending on the sampling site, finding values significantly higher at site $C$, probably because at this site there is a niche conducive to the maintenance of the biological cycle of the parasites; in particular, in recent years, a clear population growth of roe deer has been documented (data from the Emilia Romagna regional agency). A higher prevalence was detected in ticks collected in May, although the differences between the different periods of the year were not significant; conversely, other authors have shown higher prevalences in June and October [22]. The nymphs were more frequently infected than adults and larvae (all negative), but these differences were not statistically significant; in contrast, in Poland, adults showed higher levels of positivity compared to nymphs [22]; nevertheless, the latter play the main role in the spread of pathogens due to their higher number. Significant differences were not found in relation to the temperature and humidity encountered during the sampling phase of our work. Previous studies [23] had shown that when the the minimum temperature required for the activation of ticks is reached, then the temperature has a minimal effect on the progress of the diffusion of piroplasms.

Sequencing DNA identified Babesia EU1, B. capreoli/B. divergens and the Theileria buffeli/sergenti/orientalis complex. Theileria spp. belonging to this species complex are not distinguishable on the basis of analysis of the fragment amplified in the presented study, including the $18 \mathrm{~S}$ rRNA, a highly conserved region of the genome of piroplasms. This complex of species is still considered minimally pathogenic to animals (domestic and wild ruminants) and this, combined with the fact that this organism does not appear to be zoonotic, has decreased interest in this group of parasites. Moreover these species do not represent a significant risk to the health of Italian cattle [24]. Samples collected in site $\mathrm{C}$ show highest percentage of positivity. Grazing cattle are not present in this area; therefore, perhaps the reservoirs are wild ruminants even if in these animals, in Italy, this species complex has not yet been reported.

In the presented study, in 2 samples it was not possible to discriminate between $B$. capreoli/B. divergens, because analysis of the 18S-rRNA did not allow to distinguish them, as also reported in the literature. Babesia EU1, also called Babesia venatorum, was present at all samplig site, with higher prevalence at site B. This parasite is of greater 
importance because it is a zoonotic pathogen. This species has been isolated for the first time in 2 human cases, one in Austria and the other in Italy [25]. The latter involved a splenectomized human who had supposedly been infected during hunting on the Apennines at few kilometers east of the parks examined. The infected ticks analysed in the presented study were found in parks frequented by people, particularly in the nature trails, picnic areas and children's play areas. The results obtained indicate the presence of the risk of contact with infected ticks and the consequent possibility of transmission to humans of infection by Babesia EU1.

In the current study, the overall prevalence of $A$. phagocytophilum in questing ticks was $8.1 \%$, in line with studies performed in other European countries. The presence of this pathogen was recently investigated in questing ticks from other sites of the Emilia Romagna region; the first study [14] found only 2 out of 100 nymphs (2\%) positive for A. phagocytophylum, while in the second [26], none of the 115 examined were positive. These authors used conventional PCR, which is likely considered less sensitive than real time PCR used in the present study.

The presence of $B$. burgdorferi s.l. in ticks has been extensively studied in Europe; in Italy has been mainly investigated in northern regions, with prevalence ranging from $10 \%-20 \%[26,27]$. The presented results show an overall prevalence of $26.7 \%$, without significant differences between the different sampling sites.

16 samples showed concomitant infections of 2 pathogens. Concomitant infections in ticks have also been described in Europe, and the presence of A. phagocytophilum, $B$. burgdorferi s.l. and $B$. microti simultaneously in ticks also reported [28]. In the presented study, however, no more than two infectious agents were ever found in a single tick.

\section{CONCLUSIONS}

The results of this study, performed in areas not previously subjected to epidemiological investigation, contribute to the understanding and mapping of the spread of I. ricinus and assessment of the risk of the spread of infections transmitted by this vector species. The public parks in which the sampling was performed are crossed by nature trails and picnic areas and often used by families with children for recreation. Increased outdoor activities and an increase in the number of immunocompromised people increases the risk of diseases transmitted by ticks. There was a peak in the numbers of $I$. ricinus nymphs in May, and higher prevalence of pathogens in April-June, most often in nymphs, suggesting that particular precautions should be taken during the spring season. These data could provide guidelines for the precautions to be observed during periods of increased risk.

\section{Acknowledgments}

The authors express their thanks to Joy Worth and Susan Wang for their laboratory support.

Financial support was provided by the National Institutes of Health Allergy and Infectious Disease/ Evolution of Infectious Disease Program \#RO1 GM081714 in the United States, and an RFO Grant from the University of Bologna, Italy.

\section{REFERENCES}

1. Gray JS, Dautel H, Estrada-Peña A, Kahl A, Lindgren. Effects of climate change on ticks and tick-borne diseases in Europe. Interdiscip Perspect Infect Dis. 2009, Article ID 593232, 12 pages, doi:10.1155/2009/593232.

2. Kjemtrup AM, Conrad PA. Human babesiosis: an emerging tick-borne disease. Intern J Parasit. 2000; 30(12-13): 1323-1337.

3. Kubiak K, Dziekonska-Rynko J. Seasonal activity of the common European tick, Ixodes ricinus (Linnaeus, 1758), in the forested areas of the city of Olsztyn and its surroundings. Wiad Parazytol. 2006; 52 (1): 59-64.

4. Kramer VL, Beesley C. Temporal and spatial distribution of Ixodes pacificus and Dermacentor occidentalis (Acari: Ixodidae) and prevalence of Borrelia burgdorferi in Contra Costa county, California. J Med Entomol. 1993; 30 (3): 549-554.

5. Li X, Dunley JE. Optimal sampling and spatial distribution of Ixodes pacificus, Dermacentor occidentalis and Dermacentor variabilis ticks (Acari: Ixodidae). Exp Appl Acarol. 1998; 22 (4): 233-248.

6. Manilla G. Fauna d'Italia. Acari Ixodida. Edizioni Calderini, Bologna, Italy, 1998.

7. Iori A, Di Giulio A, De Felici S. Zecche d'Italia. In: Cringoli G, Iori A, Rinaldi L, Veneziano V, Genchi C (eds.). Mappe parassitologiche: Zecche. Rolando Editore, Napoli 2005.p.52-163.

8. Schwarz A, Maier WA, Kistemann T, Kampen H. Analysis of the distribution of the tick Ixodes ricinus L. (Acari: Ixodidae) in a nature reserve of western Germany using Geographic Information systems. Int J Hyg Environ Health. 2009; 212(1): 87-96.

9. Iori A, Gabrielli S, Calderini P, Moretti A, Pietrobelli M, Tampieri M P, Galuppi R, Cancrini G. Tick reservoirs for piroplasms in central and northern Italy. Vet Parasitol. 2010; 170(3-4): 291-296.

10. Galuppi R, Aureli S, Bonoli C, Caffara M, Tampieri MP. Detection and molecular characterization of Theileria sp. in fallow deer (Dama dama) and ticks from an Italian natural preserve. Res Vet Sci. 2011; 91(1): 110-115.

11. Drazenovich N, Foley J, Brown RN. Use of Real-Time quantitative PCR targeting the msp2 protein gene to identify cryptic Anaplasma phagocytophilum infections in wildlife and domestic animals. Vectorborne Zoon Dis. 2006, 1(1): 83-90.

12. Barbour AG, Bunikis J, Travinsky B, Hoen A G, Diuk-Wasser MA, Fish D, Tsao JI. Niche partitioning of Borrelia burgdorferi and Borrelia miyamotoi in the same tick vector and mammalian reservoir species. Am J Trop Med Hyg. 2009; 81(6): 1120-1131.

13. Barandika JF, Hurtado A, Juste RA, Garcia-Pérez AL. Seasonal Dynamics of Ixodes ricinus in a 3-Year Period in Northern Spain: First Survey on the Presence of Tick-Borne Encephalitis Virus. Vector-Borne Zoon Dis. 2010; 10(10): 1027-1035.

14. Maioli G, Pistone D, Bonilauri P, Pajoro M, Barbieri I, Patrizia M, Vicari N, Dottori M. Ethiological agents of rickettsiosis and anaplasmosis in ticks collected in Emilia-Romagna region (Italy) during 2008 and 2009. Exp Appl Acarol. 2012; 57(2): 199-208.

15. Dantas-Torres F, Otranto D. Seasonal dynamics of Ixodes ricinus on ground level and higher vegetation in a preserved wooded area in southern Europe. Vet Parasitol. 2013; 192(1-3) 253- 258.

16. Wilson ML. Population ecology of tick vectors: interaction, measurement and analysis. In: Sonenshine DE, Mather TN (eds.). Ecological dynamics of tick-borne zoonoses. Oxford University Press, UK, 1994. p.20-44.

17. Randolph SE, Green RM, Hoodless AN, Peacey MF. An empirical quantitative framework for the seasonal population dynamics of the tick Ixodes ricinus. Int J Parassitol. 2002; 32: 979-989.

18. Balashov YS. Bloodsucking ticks (Ixodidea) Vector of diseases of man and animals. Miscellaneous Publications of the Entomological Society of America. 1972; 8: 161-376.

19. Anderson JF, Magnarelli LA. Biology of Ticks. Infect Dis Clin North Am. 2008; 22: 195-215.

20. Jensen PM. Host seeking activity of the Ixodes ricinus ticks based on daily consecutive flagging samples. Exp Appl Acarol. 2000; 24: 695-708.

21. Hartelt K, Oehme R, Frank H, Brockmann SO, Hassler D, Kimming P. Pathogens and symbionts in ticks: prevalence of Anaplasma phagocytophilum (Ehrlichia sp.), Wolbachia sp., Rickettsia sp. and Babesia sp. in southern Germany. Int J Med Microbiol. 2004; 293 (suppl 37): 86-92.

22. Kuźna-Grygiel W, Bukowska K, Cichocka A, Kosik-Bogacka D, Skotarczak B. The prevalence of piroplasms in a population of Ixodes ricinus (Acari: Ixodidae) from North-Western Poland. Ann Agric Environ Med. 2002; 9(2): 175-178. 
23. Gray JS. Studies on the activity of Ixodes ricinus in relation to the epidemiology of babesiosis in Co Meath, Ireland. Br Vet J. 1980; 136(5): 427-436.

24. Cassini R, Bonoli C, Montarsi F, Tessarin C, Marcer F, Galuppi R. Detection of Babesia EU1 in Ixodes ricinus ticks in Northen Italy. Vet Parasitol. 2010; 171(1-2): 151-154.

25. Herwaldt B L, Cacciò S, Gherlinzoni F, Aspock H, Slemenda SD, Piccalunga P, Martinelli G, Edelhofer R, Hollstein U, Poletti G, Pampiglione S, Loschenberger K, Tura S, Pieniazek N. Molecular charcterization of a non-Babesia divergens organism causing zoonotic babesiosis in Europe. Emerg Infect Dis. 2003; 9(8): 942-948.
26. Corrain R, Drigo M, Fenati M, Menandro ML, Mondin A, Pasotto D, Martini M. Study on ticks and tick-borne zoonoses in public parks in Italy. Zoonoses Public Health. 2012; 59(7): 468-476.

27. Nazzi F, Martinelli E, Del Fabbro S, Bernardinelli I, Milani N, Iob A, Pischiutti P, Campello C, D’Agaro P. Ticks and Lyme borreliosis in an alpine area in northeast Italy. Med Vet Entomol. 2010; 24(3): 220-226. 28. Wójcik-Fatla A, Szymańska J, Wdowiak L, Buczek A, Dutkiewicz J. Coincidence of three pathogens (Borrelia burgdorferi, Anaplasma phagocytophilum and Babesia microti) in Ixodes ricinus ticks in the Lublin macroregion. Ann Agric Environ Med. 2009; 16(1): 151-158. 